Supporting Information (SI) for

\title{
Gram-scale green synthesis of copper nanowire powder for nanofluid applications
}

Nitai C. Maji and Jayanta Chakraborty*

Department of Chemical Engineering, Indian Institute of Technology Kharagpur, West Bengal, 721302, India

KEYWORDS: Copper nanowire, Nanopowder, Green Synthesis, Nanofluid, Thermal Conductivity Enhancement

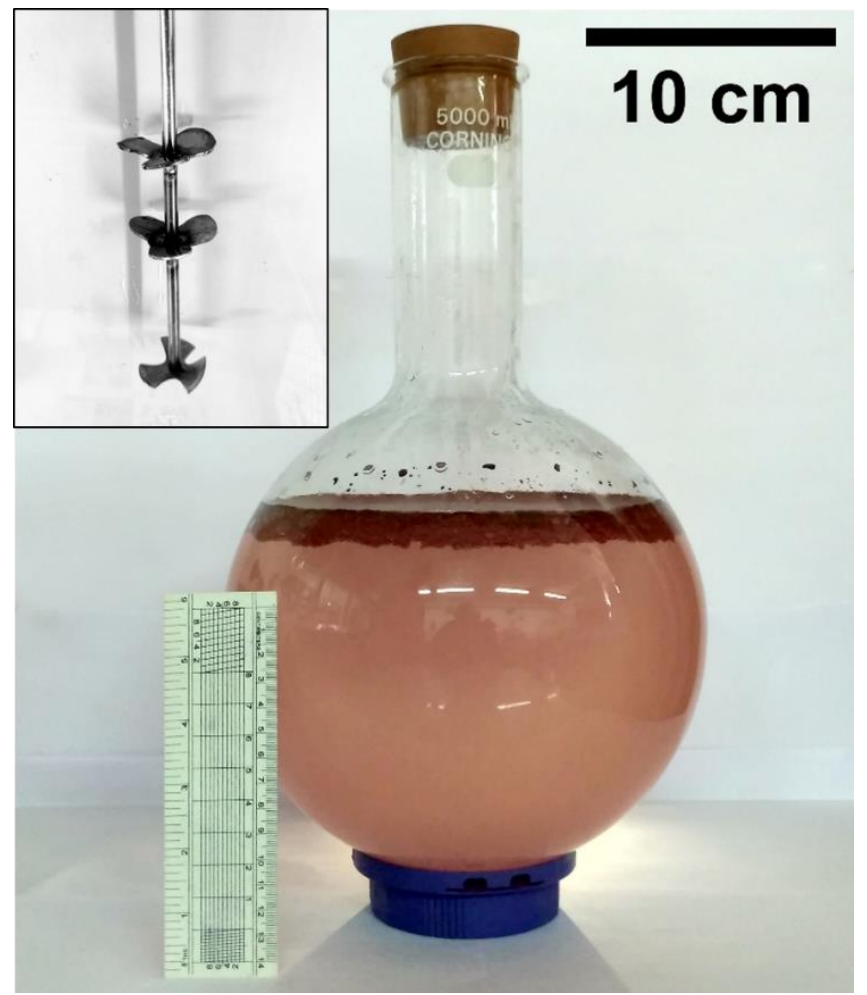

Figure S1. Photograph of large reaction vessel of 5L batch (inset: photograph of specialized stirring rod attached to overhead mechanical stirrer) 

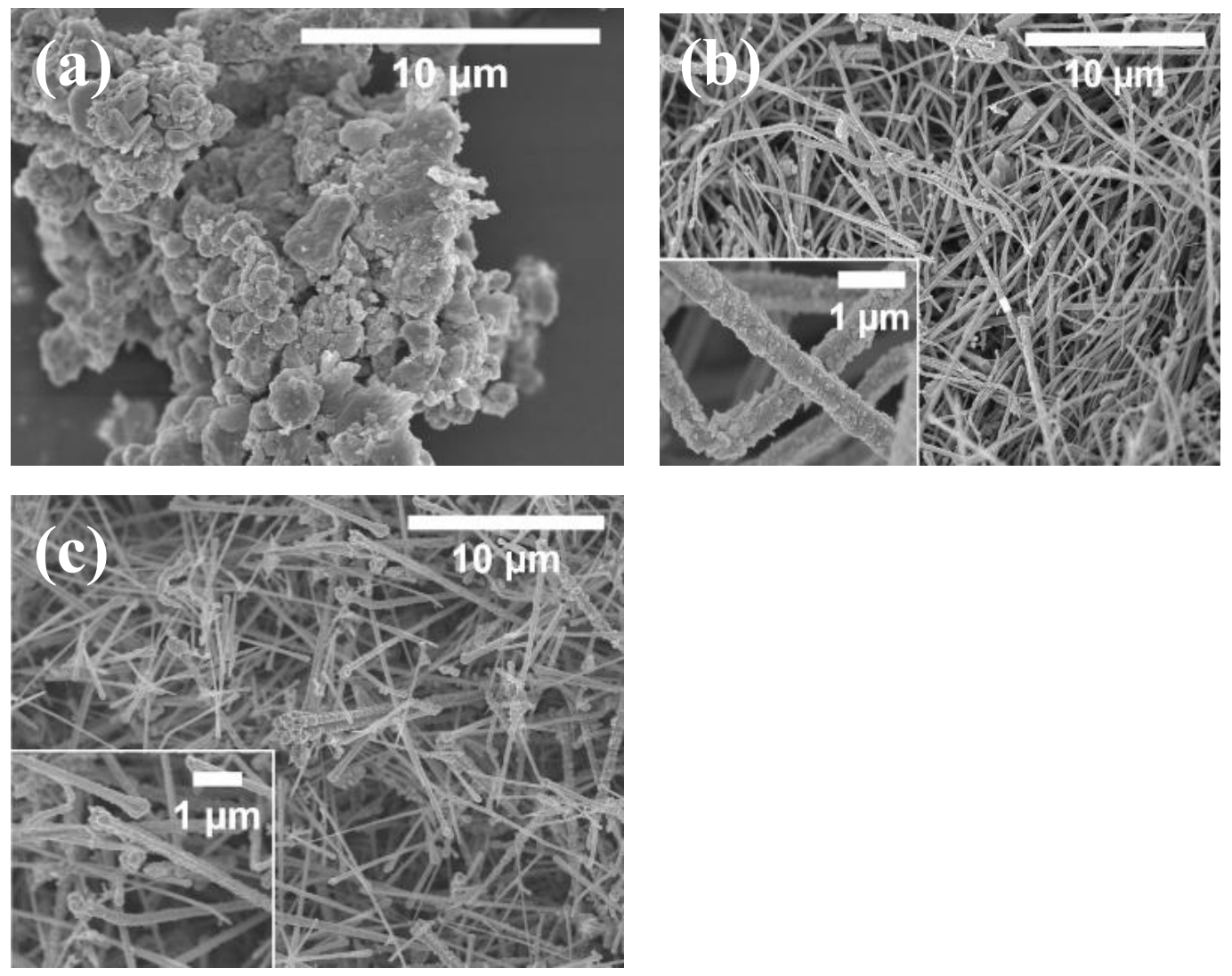

Figure S2. FESEM images of copper nanowires with EDA concentration (a) 0 M, (b) 0.03 M, (c) 0.15 M. FESEM images with higher magnification shown in inset. 

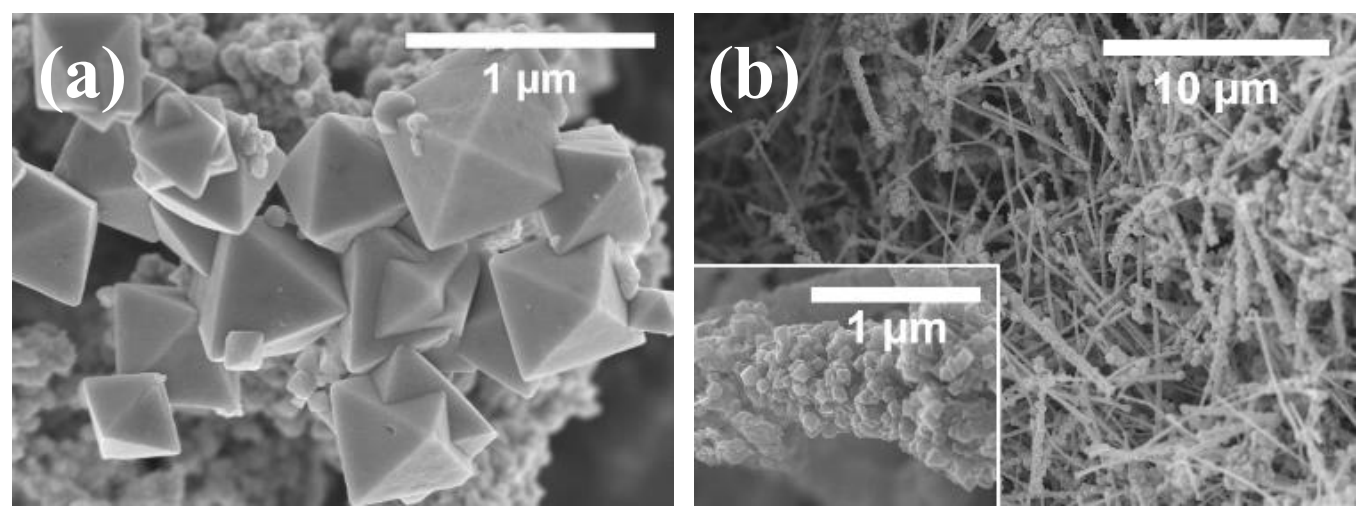

Figure S3: Copper nanowires formed with different hydrazine concentration (a) $2 \mathrm{mM}$, (b) 15 $\mathrm{mM}$. Copper nanocubes are shown in inset of (b)

\section{-Alteration in viscosity and density of CuNW-EG nanofluids}

Viscosity of the CuNW-EG nanofluids was measured by U-tube capillary viscometer and density of these nanofluids were determined by specific gravity bottles. It was found that such low volume fraction $(0.15 \mathrm{vol} \%)$ of fillers in highly viscous base fluids like ethylene glycol (viscosity: $\sim 16 \mathrm{mPa}-\mathrm{s}$ ) doesn't change (below the measurable range) the viscosity of the nanofluids significantly. Whereas, density of the copper nanofluids was increased up to $0.3-0.4 \%$ with highest particle loading of 0.15 vol $\%$. 